\title{
Same-Sex Mounting in Birds: Comparative Test of a Synthetic Reproductive Skew Model of Homosexuality
}

\author{
Aldo Poiani* \\ School of Biological Sciences, Monash University, Australia
}

\begin{abstract}
Same-sex mounting is an evolutionary paradox in that it is not directly conducive to fertilization in spite of its obvious sexual origin. Whether same-sex mounting is an adaptive behaviour that indirectly enhances reproductive success of self or close relatives through its mediation of dominance or cooperative interactions, or whether it is just a by-product of neuroendocrinological conditions manifested during breeding periods of the year is an issue that remains to be resolved. Here I introduce a novel model, the Synthetic Reproductive Skew Model of Homosexuality that aims at understanding same-sex mounting as a result of the combined effect of a set of variables and processes that affect both sexual and sociosexual aspects of behaviour. I also provide a comparative test of the model, the test is circumscribed to birds and utilises data from 72 avian taxa. Comparative analyses suggest that same-sex mounting in birds is an evolutionary result of inter-individual interactions associated with the dynamics of reproductive skew, direct effects of sexual readiness in specific social circumstances and sociosexual interactions that, in birds, seem to be more affected by dominance conflicts than by affinitive relationships.
\end{abstract}

Key Words: Homosexuality, comparative analyses, birds, reproductive skew.

\section{INTRODUCTION}

Homosexual behaviour, defined as an interaction that is unambiguously sexual or of sexual origin and that is performed between two or more individuals of the same sex, is not uncommon in the animal kingdom [1]. Engaging in sexual intercourse with a conspecific of the same sex seems to be a prima facie maladaptive behaviour as this kind of intercourse is not expected to directly lead to fertilization and reproductive success. In this context then, homosexual mounting can be regarded as an evolutionary paradox. Such evolutionary paradox could be more specifically formulated in the following manner: If unambiguously sexual behaviours such as mounting or genito-genital contact have originally evolved in the context of reproduction, why is it that they occur between members of the same sex where those behaviours cannot obviously lead to immediate fertilization?

The evolutionary paradox of homosexuality has puzzled scientists for more than a century. Whereas human homosexuality has been the focus of much scientific interest since at least the 1800s, the modern scientific study of non-human homosexual behaviour has a much more recent history $[2,3]$. The initial works, however, tended to focus on homosexual behaviour of mammals, presumably because researchers had human homosexuality in mind. For instance Havelock Ellis ([3]: 188) remarked that same-sex sexual behaviour "is common among various mammals, and, as we should expect, is especially found among the Primates most nearly below Man”. The initial reviews of same-sex sexual behaviour in

*Address correspondence to this author at the School of Biological Sciences, Monash University, Victoria 3800, Australia; Tel: +61 399055665 ; Fax: +61 39905 5613; E-mail: Aldo.Poiani@sci.monash.edu.au animals other than humans focused on female-female (F-F) rather than male-male (M-M) mounting [4, 5]. Presumably because mounter behaviour is more typical of males, thus a female mounting another female might have been perceived as a kind of "paradox within a paradox". The first full survey of both male and female same-sex sexual behaviour in nonhuman species was carried out by Anne Innis Dagg [6], who also restricted her work to mammals, reaching some major conclusions that are still valid today: same-sex mounting occurs in the context of social play, aggression, sexual excitement and non-playful physical contact. It took another 15 years, however, for students of sexual behaviour to also consider homosexuality in birds [1]. Bruce Bagemihl's book Biological exuberance: Animal homosexuality and natural diversity is a substantial compendium of the very diverse same-sex behaviours described across a large variety of animals, both vertebrates, including birds, and invertebrates. Although I disagree with some of Bagemihl's [1] propositions, such as his suggestion that same-sex sexual behaviour is a result of an "excess of energy" available to animals that is used in activities with no adaptive purpose (or just for fun) (see also criticisms by Harvey [7] and Roughgarden [8]), I regard his effort at searching for homosexual behaviour in reports of very diverse taxa as praiseworthy. The most recent reviews of animal homosexual behaviour are the book edited by Volker Sommer and Paul Vasey [9] that also includes two chapters on birds; and the article of McFarlane et al. [10] that is the first comparative study of same-sex sexual behaviour in birds that uses modern comparative analytical methods.

To a great extent, the specific mechanisms purported to explain the evolution and maintenance of homosexual behaviour are similar for birds and mammals, even though 
taxa-specific trends are also clear [11]. Poiani and Dixson [11] list 76 explicative hypotheses of homosexual behaviour that have been proposed across taxa by various authors over the years and that span different levels of analysis [12]: a) proximate causation, b) adaptation, c) ontogeny and d) evolution. In their comparative analyses of birds and mammals Poiani and Dixson [11] conclude that same-sex mounting is more prevalent in mammals than birds, this difference is associated with a greater degree of sociality and cooperative breeding in mammals that can favour both sexual and sociosexual (dominance, affiliation) expressions of same-sex mounting. The greater prevalence of polygamy among mammals also favours same-sex mounting that is especially manifested during periods of segregation of males in monosexual groups. Differences in tertiary sex ratio biases, with sex ratios being more female-biased in mammals, can also contribute to explaining the higher involvement of female mammals than female birds in same-sex mounting, via both sexual and sociosexual mechanisms. After carrying out a multi-species comparative analysis, McFarlane et al. [10] concluded that same-sex mounting in male birds is associated with polygamous mating systems, whereas in female birds it is more prevalent in monogamous mating systems, especially among precocial species. The pattern found among females is explained by McFarlane et al. [10] as a result of pair bonding that develops between them, whereas the pattern described in males is explained as a result of competition among males, such male-male competition being characteristic of polygynous mating systems.

Some authors have also carried out detailed studies of same-sex mounting in single bird species. Some of the results of such studies are consistent with what the above authors found in their multi-species comparative analyses $[10,11]$. For instance, male-male (M-M) or female-female (F-F) sexual behaviours may be a consequence of a biased sex ratio and the establishment of social bonding, especially in species where polygamy is common. Among polygamous species that exhibit inter-individual social bonds, two males or two females may tend to pair because in most circumstances the bond is also extended to an individual of the opposite sex to form a polygamous trio $[13,14]$. If the sex ratio is biased, however, the population may exhibit some cases of same-sex pair-bonded individuals. Such same-sex pair bonding could lead to a homosexual relationship if, following our definition, homosexual mounting does occur. If sociallybonded males or females do not engage in mounting or other unambiguously sexual behaviours, then I prefer to use the term homosociality, rather than homosexuality. Formation of alliances during the mating season was also highlighted by Kotrschal et al. [13] and King [14], here mounting between allied individuals may be proximately caused by the activity of neuroendocrine mechanisms associated with breeding.

In sum, results of previous studies suggest that although same-sex mounting is less prevalent in birds than mammals, when it occurs it is more often than not associated with polygamous mating systems, polygyny in particular, presumably because such systems intrinsically bias the operational sex ratio towards females thus leaving many males with little or no access to females during the reproductive period/s of the year. Same-sex mounting also occurs in sociosexual contexts of dominance or affiliation associated with social bonding.
In spite of their value as pioneering works, previous studies do have some important shortcomings. Two of the most obvious ones are: a) the limited number of variables that have been analysed so far and, above all, b) the lack of a specific theoretical framework that could synthesise, in an evolutionary perspective, the diversity of patterns found across individual species. In this work I aim to provide such a broad theoretical framework through a model that is derived from an extension of Reproductive Skew theory. I will also test a series of predictions of the model through a comparative analysis of 72 avian taxa in which 14 behavioural and life-history variables, that include body mass, are considered.

\section{THE MODEL}

Here I introduce what I term the Synthetic Reproductive Skew Model of Homosexuality. The model is based on Reproductive Skew theory and it is termed Synthetic because, on the one hand, it extends classic Reproductive Skew theory to include additional and very important variables, such as mate choice, inbreeding avoidance, early ontogeny effects and queuing for breeding. On the other hand, it is also termed Synthetic because, as we will see, it unifies three major theoretical aspects of evolutionary studies of same-sex sexual behaviour: reproductive skew, sexual aspects of homosexual behaviours and sociosexual aspects of homosexual behaviours. Both [11] and this article especially emphasise the second meaning of the term Synthetic. Due to the complexity and number of variables involved, the model will be formulated in a qualitative manner that, however, will still be capable of producing specific predictions that I will test through a comparative analysis.

Modern Reproductive Skew theory has its immediate precursors in the pioneering works of Mary Jane West-Eberhard [15], Steve Emlen [16, 17] and Sandra Vehrencamp [18, 19]. The initial models $[18,19]$ highlighted the conflicts between dominant and subordinate over dispersal, reproduction and allocation of resources that ultimately result in differential reproductive output. The difference in reproductive success between dominant and subordinate is the chief measurement of reproductive skew. In these models reproductive skew increases when group breeding is more productive than solitary breeding and when the degree of genetic relatedness between dominant and subordinate increases.

Emlen [20] applied Reproductive Skew theory to the evolutionary dynamics of vertebrate family groups. In family groups offspring may delay dispersal (e.g. because of ecological constraints) and stay at home in close association with their parents waiting for an opportunity to become a breeder. The higher the probability for successful offspring dispersal, the higher the "incentive to stay" parents should offer their offspring in order to retain them in the family and benefit from their help [21]. The lower the probability of successful dispersal, the greater the leverage parents have in order to extract some kind of benefit from the retention of offspring without providing "incentives".

Reeve and Keller [22] proposed a general formulation for Reproductive Skew models that is an extension of Hamilton's Rule [23]. Let us imagine the realistic possibility that within a social unit individuals could adopt more than one strategy or behaviour. Let us also assume that there are two alterna- 
tive strategies to choose from: $i$ and $j$. Hamilton's Rule is used to decide which one of those two alternative strategies will be favoured by natural selection. For instance, strategy $i$ will be selected over $j$ if:

$$
(\mathrm{P} i-\mathrm{P} j)+r(\mathrm{~K} i-\mathrm{K} j)>0
$$

Where $\mathrm{P}$ is the individual's reproductive output associated with the strategy, whereas $\mathrm{K}$ is the other party's reproductive output if any of the two strategies is performed, and $r$ is the coefficient of relatedness between the interactants. Within this framework, if strategy $i$ is "defer reproduction and behave homosexually" (i.e. P $i=0$ ), then the strategy will be selected over an alternative strategy $j$ (e.g. "behave heterosexually and reproduce") if

$$
r(\mathrm{~K} i-\mathrm{K} j)>\mathrm{P} j
$$

That is, homosexuality will be selected if the net gain in reproductive output enjoyed by close relatives when the individual behaves homosexually, corrected by the coefficient of relatedness between the two, is larger than the reproductive output of the homosexual had s/he decided to engage in heterosexual sexual behaviour and reproduce instead.

The above formulation has been extended by Reeve and Emlen [24] for the case of an $\mathrm{N}$-individual group size to give:

$$
\mathrm{P} i-\mathrm{P} j+\sum_{m=1}^{N-1} \mathrm{r}_{m}\left(\mathrm{~K}_{m, i}-\mathrm{K}_{m, j}\right)>0
$$

In our extension of Reproductive Skew theory to homosexuality, $\mathrm{K}_{m, i}$ is the reproductive output of the $\mathrm{m}^{\text {th }}$ group member if a group mate behaves homosexually, $\mathrm{K}_{m, j}$ is the reproductive output of the $\mathrm{m}^{\text {th }}$ group member if the mate behaves heterosexually instead and $r_{m}$ is the coefficient of relatedness between the two.

Under the conditions I am considering in this model, selection of homosexual behaviour should therefore occur when

$$
\sum_{m=1}^{N-1} \mathrm{r}_{m}\left(\mathrm{~K}_{m, i}-\mathrm{K}_{m, j}\right)>\mathrm{Pj}
$$

This predicts a higher threshold of independent reproductive output where homosexuality could be selected if the group is of an intermediate size, especially for a group formed by close relatives. In other words, an individual is more likely to develop a homosexual sexual orientation in intermediate groups of close relatives where its lack of reproduction has a more significant effect on the reproductive success of the rest of the group. In very large groups the values of $\mathrm{K}$ are probably too small, in very small groups they are presumably larger but they add up across a smaller number of group members.

The classic Reproductive Skew theory that I introduced above could explain homosexual behaviour mainly on the basis of the lack of opportunities subordinates may have to reproduce heterosexually within a group, such lack of opportunities are dictated by the inability of the subordinate to disperse, and the control exerted by the dominant over reproduction, a control that may affect the subordinate at various stages of its ontogeny. Thus homosexuality may simply be the sexual expression of individuals who are not engaging in reproduction, with such sexual expression also having, at least potentially, specific adaptive value for the subordinate in terms of establishing affinitive relationships with dominants and other subordinates, and also as a manner of establishing dominance relationships with other subordinates. Dominants may also participate in homosexual mounting for the same reasons, but in their case same-sex sexual behaviour is obviously expressed within a bisexual orientation, whereas if subordinates do not copulate with any individual of the other sex, they will be expressing a fully homosexual behaviour.

Recent developments of Reproductive Skew theory, however, have highlighted the need to incorporate other, very important variables that are well known to affect the distribution of reproductive success among individuals in a population. For instance, in some societies breeder status may be achieved through an age-based queuing system, in which the eldest subordinate is the one becoming breeder upon the death of the dominant. In queuing systems that are either unstable or stable in the short term but subject to high turnover in the medium term the probability of development of homosexual (i.e. non-reproductive) phenotypes may decrease. This is expected from the higher chances of subordinates to exact some reproductive success in the short term when the queuing system is not highly constraining. Another important aspect of dominant-subordinate interactions that should be incorporated in any reproductive skew model of homosexuality is dominant's interference with the early subordinate's ontogeny. The dominant, that is usually older than the subordinate, has the advantage of interacting with subordinates since the time the latter are young. This confers an advantage to the dominant in terms of perhaps manipulating the behavioural development of subordinates, especially during their early ontogeny, so that the subordinate may be less likely to disperse and more likely to stay and help once s/he has become an adult, while at the same time not representing a reproductive competitor if the subordinate develops a homosexual sexual orientation $[25,26]$.

Mate choice may also increase the probability of expression of homosexual behaviours during the breeding periods of the year in individuals that are not preferred partners for heterosexual copulations. Subordinate males, for instance, may have little chance of breeding if females do not prefer them as mates. Such female choice may lower the threshold conditions for the expression of homosexuality in males and this may occur in both monogamous and polygamous mating systems [27] depending on the level of bias in the sex ratio. The same is obviously true in the case that the sex ratio is female biased and males also exert some mate preference, in this case homosexual behaviours may be expressed in females.

In addition to mate choice, when the group is formed by closely related individuals, incest avoidance may also decrease the probability of heterosexual matings thus, again, lowering the threshold for selection of homosexual partnerships [27-29]. Paradoxically, although incest avoidance may increase the chances for the expression of homosexual be- 
haviour due to increased reproductive skew, it may also decrease the likelihood of homosexual intercourse occurring between closely related members of a social unit (e.g. a family), if the incest avoidance mechanisms that are adaptive in the heterosexual context, remain active in the homosexual context as well. Therefore the combined effects of reproductive skew and incest avoidance lead to the prediction that homosexuals, when they occur, will tend to preferentially engage in sexual intercourse, especially when they are adult, with non-kin or with kin that are not first degree (e.g. cousins).

The Synthetic Reproductive Skew Model of Homosexuality is shown in Fig. (1). The model involves the amalgamation of three major theoretical aspects of animal homosexuality: a) Reproductive Skew Theory modified to also take into account aspects of mate choice and inbreeding avoidance (blue section of Fig. 1); b) sexual aspects of homosexual behaviour (green section of Fig. 1) and c) sociosexual aspects of homosexual behaviour (purple section of Fig. 1).

\section{Some Predictions of the Synthetic Reproductive Skew Model of Homosexuality}

In spite of its qualitative formulation, the Synthetic Reproductive Skew Model of Homosexuality clearly makes the following broad predictions, some of which I am going to test in birds using a comparative analysis:

1) Ecological constraints to dispersal favour philopatry [16] and set the stage for the manifestation of homosexual behaviour in either sexual or sociosexual contexts as individuals of the same sex are more likely to encounter each other.

2) Philopatric conspecifics may form social groups when benefits of group living exceed costs [30] and, again, close interactions among group mates may give raise to either sexual or sociosexual expressions of homosexuality. Frequency of homosexual behaviours should be higher at intermediate group sizes.

3) In social species with reduced natal dispersal group members may include closely related individuals [16, 31]. Although group members may tend to avoid samesex sexual behaviours with close relatives, not so closely related members of a group (e.g. cousins) may engage in cooperative interactions that could be mediated by affinitive behaviours such as grooming but also same-sex reciprocal mounting. Whether a mainly positive or negative correlation is selected between same-sex mounting and degree of relatedness between interactants will probably

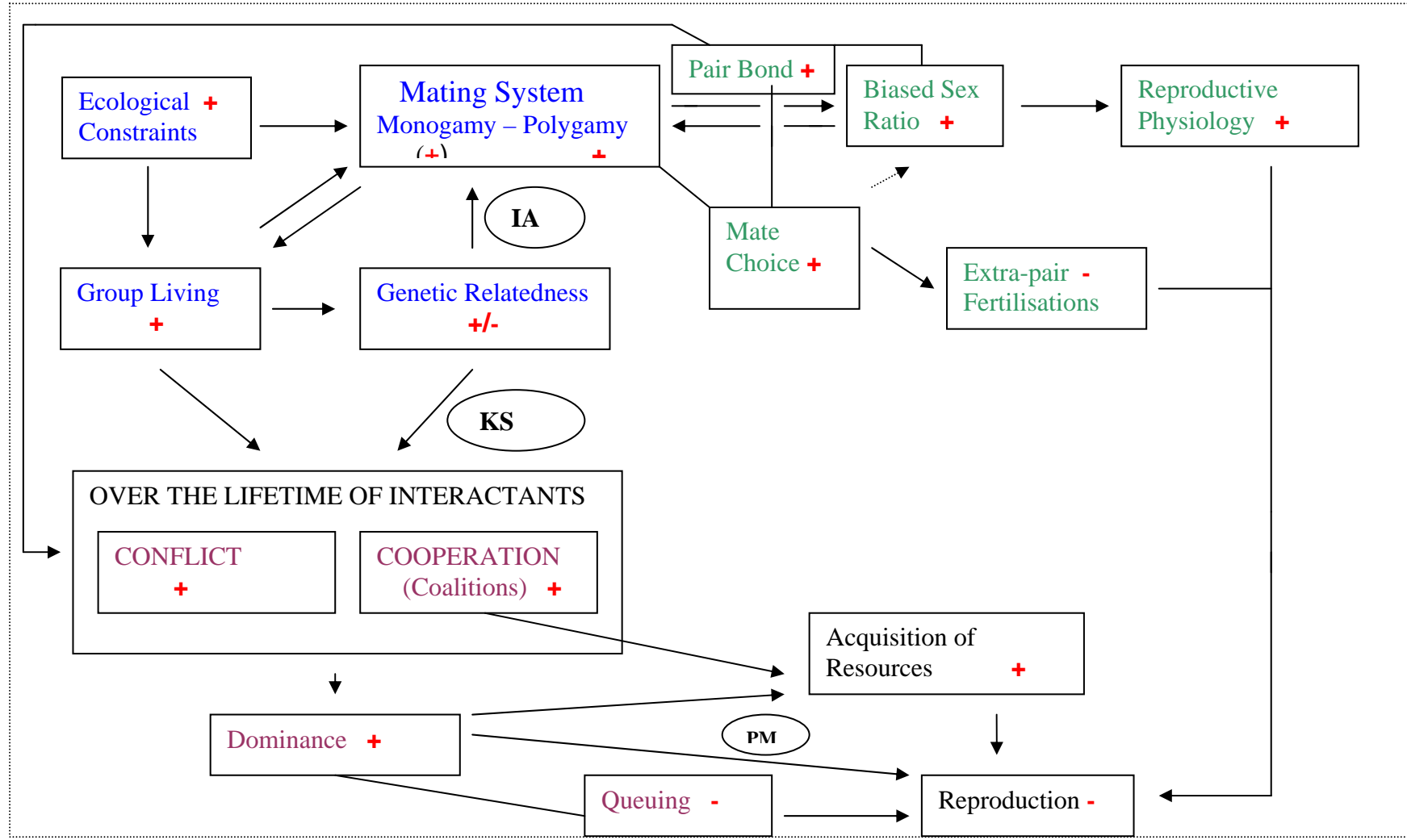

The model involves the amalgamation of three major theoretical aspects of animal homosexuality: a) Reproductive Skew Theory modified to also take into account aspects of mate choice and inbreeding avoidance (blue section); b) sexual aspects of homosexual behaviour (green section) and c) sociosexual aspects of homosexual behaviour (purple section). The links between diverse variables are either directional causal links (arrows) or non-causal (i.e. correlational) associations between variables (straight lines). For instance the mating system is linked to a biased sex ratio through an arrow. The "+" or "-“" sign inside a box indicate the sign of the slope of the correlation between that variable and same-sex sexual behaviour. For instance, the "+" sign inside the "Biased Sex Ratio" box indicates that as the sex ratio becomes more biased same-sex sexual behaviour becomes more likely or frequent. IA $=$ inbreeding avoidance, KS $=$ kin selection and $\mathrm{PM}=$ parental manipulation.

Fig. (1). A synthetic reproductive skew model of homosexuality. 
depend on the level of inbreeding depression caused by consanguineous heterosexual matings [32]: higher levels of inbreeding depression will shift the balance towards a negative correlation between genetic relatedness and same-sex mounting.

4) Ecological constraints, group living and inbreeding avoidance may all contribute to shape the mating system of the species [33]. Both monogamy and polygamy may give raise to homosexual behaviours, with a probable bias towards higher levels of same-sex mounting observed in polygamous species, as polygamy is especially likely to bias the operational sex ratio.

5) Five major elements of reproductive biology associated with the mating system can co-contribute to the manifestation of same-sex sexual behaviours from a purely sexual perspective: (a) If the mating system is such that there is a biased sex ratio among breeders, (b) those individuals not engaging in heterosexual sexual behaviour during the mating period may nevertheless copulate with alternative individuals such as same-sex partners. (c) Pair bonding behaviour that may have been originally selected in a heterosexual context [34] may continue to operate in the new homosexual context. (d) Mate choice that may have also been selected in a heterosexual sexual context [35], may continue to operate in the new homosexual context during the periods of breeding. All the above factors (a) to (d) contribute to the expression of same-sex sexual behaviours because they either limit the availability of heterosexual partners during periods of elevated sexual activity or promote bonding of same-sex partners for short or even long periods. However (e) opportunities for extra-pair fertilizations may decrease the likelihood of homosexuality in this purely sexual context. That is, this sexual module of the model clearly predicts that homosexuality during the breeding season is less likely to occur if all sexes have free access to members of the other sex for copulations and more likely to occur if such access is restricted.

6) The reproductive skew module of the model links up with the final, sociosexual module through group living and genetic relatedness, whereas the sexual module links directly with the sociosexual module through pairbonding. Within a group, it is predicted that same-sex mounting may be associated with specific conflictive or cooperative interactions. The link with the sexual module through pair bonding also indicates that same-sex sexual behaviour may be preferred in the sociosexual context of conflict over an alternative aggressive behaviour or in the context of cooperation over grooming behaviour under the influence of the reproductive condition of the individuals. In other words, depending on the context, samesex mounting may be a sociosexual manifestation of conflict or cooperation, especially during periods of heightened heterosexual sexual activity (e.g. mating season).

7) Homosexual behaviour, by favouring coalition formation in its affinitive sociosexual function or by reinforcing dominance in its competitive sociosexual function, may lead to acquisition of resources that could then be used for reproduction (here bisexuality is predicted) or to the reproduction of one of the partners in the relationship through kin selection (here strict homosexuality of one of the partners is a clear possibility).

8) Parental manipulation [36] may also contribute towards biasing the development of offspring towards a homosexual phenotype under the general effect of the inclusive fitness costs and benefits of having a homosexual offspring.

Finally,

9) A dominance hierarchy based on short queues for breeding status [37], along with direct access to reproduction are expected to decrease the manifestation of homosexuality.

\section{MATERIALS AND METHODOLOGY}

A total of fourteen variables were studied across 72 avian taxa, with data coming from an extensive literature search and direct consultation of original sources or reviews [11]. Categorical variables were numerically coded and intraspecific variability was factored in by assigning a mean value of the trait for a species based on the values for that species that were reported by various authors, whenever more than one value was available. The variables are: Mating System (facultative promiscuity, monogamy, lek, facultative polygyny, polygynandry, polygyny, polyandry, harem polygyny, occasional polygyny, polygamy, promiscuity, facultative polygamy, facultative polyandry, facultative harem polygyny). Coding of mating system categories ranged from 1 to 5 spanning from monogamy (1) to promiscuity and polygynandry (5). In this case, the value of the code for mating system increased with the qualitative increase in the number of heterosexual sexual partners involved. Sociality (colonial, territorial, group living, loosely colonial, semi-social, social, solitary, facultatively social, loose group, flock). Sociality was coded from 1 to 3 , with solitary or pair territoriality being coded 1 and sociality/coloniality being coded 3, facultatively social, semi-social or loosely group living species were coded 2. Same-sex mounting was either observed (code $=2$ ) or not (code $=1)$, with intermediate values also being possible due to intra-specific variability. Sex Involved in same-sex mounting could be males only, females only or both. When both sexes are involved in same-sex mounting, their relative frequencies could be similar or different, in the latter case males or females may be the sex with the highest reported levels of same-sex mounting. Therefore this variable was entered in the analysis coded as follows: no samesex mounting reported (code 1), M only (2), $\mathrm{M}>\mathrm{F}$ (3), $\mathrm{M}=\mathrm{F}$ (4), F>M (5) and F only (6), that is, the higher the value of the variable, the higher the relative level of female involvement in same-sex mounting. Adult sex ratio was subdivided into five states spanning from heavily female-biased adult sex ratios $(\mathrm{M}<<\mathrm{F}$, code 1) to $\mathrm{M}<\mathrm{F}(2), \mathrm{M}=\mathrm{F}(3), \mathrm{M}>\mathrm{F}$ (4) and $M>>F(5)$, that is the larger the value of the variable, the more male-biased the adult sex ratio is.

Information of homosexual mounting being explicitly performed in a sociosexual context of dominance (Dominance Mount) was recorded as N (code 1) (the authors explicitly describe a lack of same-sex mounting behaviour when discussing the behavioural repertoire associated with dominance), Y (2) (same-sex mounting is described as a sociosexual manifestation of dominance), Ya (3) (as for Y but in this case the authors explicitly state that the dominant in- 
dividual is always the mounter). Affiliative Mount describes cases of same-sex mounting performed in contexts of affiliation which usually manifests itself as bouts of reciprocal mounting. Codification in this case is either absence $(\mathrm{N}$, code 1) or presence (Y, code 2). Degree of genetic Relatedness within the group, flock or colony was categorised as either Non-related (N, code 1), Low (2), Medium (3) or High (4).

The Social Unit involved could vary from a family group, a flock or a colony according to the species, here direct values of number of individuals observed were used and they were entered in the analysis after log-transformation. Ecological Constraints are very difficult to measure for such a diverse number of species therefore we used a proxy variable that, at least in part, reflects the degree of ecological constraints faced by the population. Species typically characterized by a Cooperative Breeding system (CB, code 2) are also typically under elevated ecological constraints (e.g. limited dispersal, high predation, etc.), whereas Non-cooperatively Breeding species (NCB, 1) are comparatively less ecologically constrained (e.g. less impediments for young individuals to disperse and breed independently). Plumage Sexual Dichromatism in birds will be codified as 1 for sexually monochromatic species, 2 for species with only a mild sexual dichromatism and 3 for sexually dichromatic species. Heterosexual Pair Bonding may be either present (Y, code 2 ), absent ( $N$, code 1$)$ and for a limited group of species it may be absent but social bonds may nonetheless occur between dominant and subordinate males at a lek $(\sim$ Y, code 1.5). I also collected published information about the levels of Extra-pair Copulations (EPC). On this regard, for each species I could collect information about either EPC or Extra-pair Paternity (EPP), but usually not both. Obviously, raw values of EPC and EPP cannot be mixed up in the same analysis as they represent two different variables. In order to tackle this problem and yet use the full dataset in the comparative analyses I divided the percentages of EPC and EPP into 5 broad levels: No EPC (or EPP) (0\%, code 1), Low $(>0 \%-3 \%$, code 2$)$, Medium (>3\%-10\%, code 3$)$, High (> $10 \%-40 \%$, code 4$)$ and Very High ( $>40 \%$, code 5$)$. Finally I collected information about Body Mass $(\mathrm{kg})$ for each species.

I tested the model through a comparative analysis of independent contrasts [38]. The phylogeny used is that appearing in Fig. (2) that is a compound of phylogenetic information derived from various sources. Higher level nodes were assigned following Sibley and Ahlquist [39], Mindell et al. [40], Slack et al. [41] and Livezey and Zusi [42]. Several Orders did not require the availability of a within-Order phylogeny as the number of species was either one or two: Apodiformes, Pelecaniformes, Columbiformes, Procellariiformes, Piciformes, Sphenisciformes, Gruiformes and Falconiformes; they only required a higher order phylogeny for their placement in relation to the other Orders. The remaining aspects of the tree topology were assigned following Sibley and Ahlquist [39] (Psittaciformes), Livezey and Zusi [42] (Struthioniformes), Livezey [43] (Anseriformes), Sibley and Ahlquist [39] and Sheldon and Slikas [44] (Ciconiiformes), Sibley and Ahlquist [39] (Phoenicopteridae), Friesen et al. [45], Chrocet et al. [46], Thomas et al. [47], Baker

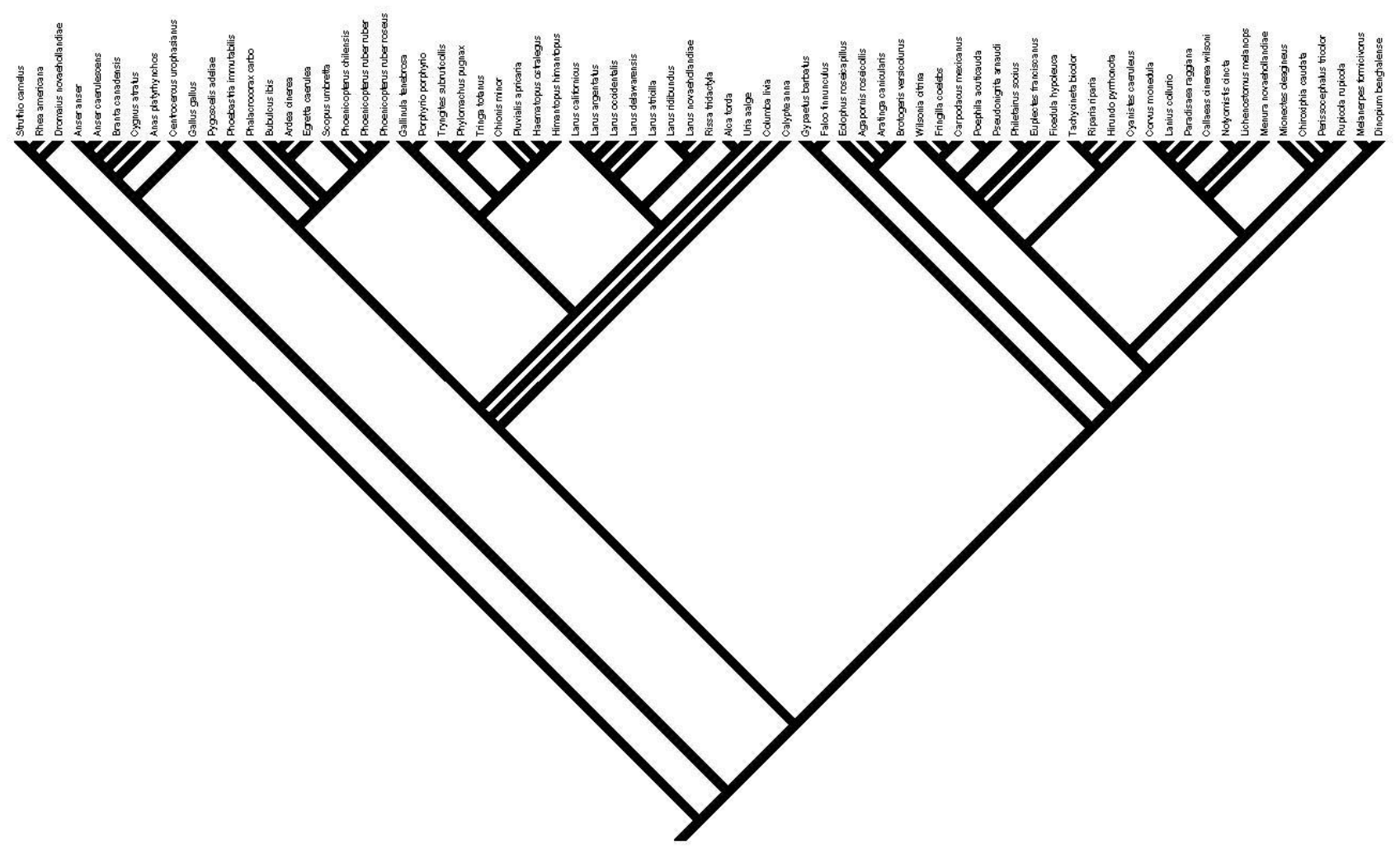

Fig. (2). Phylogenetic tree of the avian taxa used in the comparative analyses. 
et al. [48] and Fain and Houde [49] (Charadriiformes), Christidis [50], Sibley and Ahlquist [39], Irestedt et al. [51], Ericson and Johansson [52], Barker et al. [53], Spicer and Dunipace [54], Sheldon et al. [55] and Treplin [56] (Passeriformes).

Calculation of phylogenetically independent contrasts was carried out using the PDAP program [57] that runs in the Mesquite program of Maddison and Maddison [58]. All analyses were run twice: once after setting all branch lengths of the phylogenetic tree equal to one, this approximates a punctuational mode of character evolution, followed by a second run of the program with branch lengths set following Grafen's method [59]. The procedure was to first correlate phylogenetically independent contrasts for all variables with $\log$ (Body Mass + 1) contrasts and subsequently correlate all variables with each other after controlling for the effect of body mass.

\section{RESULTS}

None of the variables is significantly correlated with $\log$ (Body Mass + 1) contrasts (results not shown) with the exception of Adult Sex Ratio contrasts which significantly decreased with $\log (\mathrm{BM}+1)$ contrasts (Pearson's product moment correlation $r=-0.238, P=0.039, n=54$ ) at least when branch lengths were assigned using Grafen's method [59]. That is, in birds, evolutionary trends towards increasing body mass seem to be associated with an evolutionary trend towards a female-biased adult sex ratio. However this is unlikely to explain per se the association between same-sex mounting and adult sex ratio that I will describe below, simply because same-sex mounting is not associated with body mass.

In general, the sign of the coefficient of correlation tends to be concordant between the two methods of branch length assignment, although Grafen's method produced the highest number of significant results. Therefore I will only report the results obtained with Grafen's method. Results are summarised in Table 1, all probabilities are one-tailed. Overall, 15 statistically significant correlations were obtained that in general tend to support the Synthetic Reproductive Skew Model of Homosexuality.

The two strongest correlations are the one between Plumage Sexual Dichromatism contrasts and Mating System contrasts, and the one between Same-sex Mounting contrasts and Sex Involved contrasts. That is, as it is already well known from the literature, evolutionary changes towards polygamy are associated with evolutionary changes towards increased plumage sexual dichromatism in birds. It also appears that in birds evolutionary trends towards the expression of same-sex mounting are strongly positively associated with evolutionary trends towards a greater involvement of females in same-sex mounting. This result could be linked to the trend for same-sex mounting to be positively associated with Sociality and (marginally not significantly) to Dominance Mount (see Table 1). That is, in social birds where females establish dominance hierarchies, such dominance tends to be expressed through same-sex mounting; e.g. Porphyrio porphyrio.

Another result that links life-history traits and the evolution of polygamy is the decrease of pair bond with both increased plumage sex dichromatism, and increased polygamy.
This result is easily explained by the fact that in the species included in this work, pair bond mainly refers to malefemale associations in a mainly socially monogamous mating system. Thus it is not surprising that evolutionary trends towards polygamy are associated with evolutionary trends towards decreased pair-bond. If broader social bonds are considered (e.g. colonial living), then our results suggest that increased evolutionary trends towards sociality are associated with evolutionary trends towards polygamy. Evolutionary trends towards increased ecological constraints to dispersal are also positively associated with evolutionary trends towards polygamy in our sample of species.

More importantly, additional significant results support the more specific predictions of our model. In particular, same sex mounting increases with a) an increase in malebiased sex ratio, and b) an increase in evolutionary trends towards sociality, the latter being also associated with c) an increase in same-sex dominance mounts. Higher same-sex dominance mounts also tend to increase as the sex-ratio becomes more male biased, suggesting that the establishment of dominance among males can be mediated by same-sex mounting, as it does for females (see above).

As social unit size tends to increase over evolutionary time, same sex mounting tends to decrease, this being particularly true for affiliative same-sex mounting. This result is predicted by our model if the average group size was large, which is probably the case in our sample as many of the species included live and/or breed in relatively large colonies.

Evolutionary trends towards dominance same-sex mounting are associated with evolutionary shifts towards plumage sexual monomorphism. This trend may result from the marginally non-significant evolutionary association of sexual plumage monomorphism with increased sociality (see Table 1).

With regard to relatedness, I detected a significant evolutionary trend in birds for increased relatedness to be associated with an increased level of male-bias in the sex ratio. This can be easily explained by the well known pattern found in birds for males to be the philopatric sex, thus the more males there are in an avian colony, social group or population the more likely it is that the individuals will be more closely related.

As the degree of relatedness between interactants increases, there is a trend for dominance mounting to also increase. Reproductive Skew theory predicts this result if same-sex dominance mounting has a function in the control of subordinate reproduction. The more closely related dominant and subordinate are, the easier it should be for dominants to skew reproductive success in their favour. Following our model, this suggests that the degree of intra-social group relatedness in the species considered was probably not very high.

If the critical $\alpha$ value is corrected using the Dunn-Šidák method $\left[\alpha^{\prime}=1-(1-\alpha)^{1 / n}\right.$ where $n=$ number of tests carried out], then, given that the number of tests was 78 , it follows that $\alpha^{\prime}=0.00065$. With this new critical value only two correlations remain statistically significant: Plumage Sexual Dichromatism contrasts vs. Mating System contrasts, and the one between Same-sex Mounting contrasts and Sex Involved contrasts. 
Table 1. Pearson's Product-Moment Correlations $(r)$ between Standardized Independent Contrasts of all the Behavioural and Life-History Variables. Values Shown are $r, P$ (Sample Size)



Bold $*$ = significant at the Dunn-Šidák corrected $\alpha$, where the 0.05 level is equivalent to $0.00065 . *$ significant at the uncorrected $\alpha$ of 0.05 . ${ }^{a}=$ marginally not-significant result at the uncorrected $\alpha(0.1>P \geq 0.05)$.

\section{DISCUSSION}

Notwithstanding the more restrictive results obtained by applying the Dunn-Šidák correction to the critical value $\alpha$, broader trends emerging from the analyses suggest that the Synthetic Reproductive Skew Model of Homosexuality provides a good representation of the major variables that seem to have played a significant role in the evolution of same-sex mounting in birds. The Synthetic Reproductive Skew Model emphasises traditional and non-traditional components of Reproductive Skew theory and it also includes sexual and sociosexual aspects of same-sex mounting. The results obtained do support the need for such a synthetic approach. On the one hand, data on same-sex mounting were gathered by the various authors during the mating periods of all the species, therefore mounting obviously coincided with the neuroendocrinological conditions that characterise readiness to breed. Evolutionary changes towards the expression of same- 
sex mounting are associated with greater involvement of females in the expression of the behaviour. This trend however, simply builds on the evolutionary shifts towards samesex mounting already contributed by the involvement of males, as the adult sex ratio becomes more male-biased. I also detected a pattern for increased levels of sociality to be associated with increased expression of same-sex mounting, dominance same-sex mounting in particular, as expected from the sociosexual functions of the behaviour. This is especially relevant for sexually plumage monomorphic species. Moreover, evolutionary changes towards larger groups tend to be associated with evolutionary changes towards decreased same-sex mounting as expected from the model at larger group sizes. When group size is large, opportunities for heterosexual mounting increase for a large proportion of the individuals and hence same-sex mounting decreases, especially in the sexual context. Sociality is associated with sociosexual mounting linked to dominance, but affiliative same-sex mounting decreases with increase in the size of the social unit. That is, sociosexuality in birds seems to be biased towards the expression of reproductive conflicts more than affiliation in social species. In fact, as extra-pair copulations (EPCs) increase, affiliative same-sex mounting tends to decrease, although only marginally so $(P=0.06)$.

Although the model does provide important insights into the evolution of same-sex sexual mounting in birds, it should still be considered a partial model as important variables such as specific genetic, neuroendocrine and early developmental factors were not directly considered. The most thorough and updated, to the best of my knowledge, analysis of the major factors that could potentially affect the evolution and development of homosexual behaviour in both birds and mammals, including humans will be soon available in [11].

\section{CONCLUSION}

In conclusion, during the evolution of birds homosexual mounting has appeared in various taxa as a result of interindividual interactions associated with a) the dynamics of reproductive skew, b) effects of sexual readiness in specific social contexts and c) sociosexual interactions that, in birds, seem to be more a manifestation of dominance conflicts than affinitive relationships.

\section{REFERENCES}

[1] Bagemihl B. Biological exuberance: Animal homosexuality and natural diversity. New York: St. Martin's Press; 1999.

[2] Zuckerman S. The social life of monkeys and apes. London: Kegan Paul; 1932.

[3] Ellis H. Psychology of sex. London: William Heinemann; 1946.

[4] Beach FA. In: Diamond M, Ed. Perspectives in reproduction and sexual behaviour, Bloomington, Indiana University Press 1968; 83131.

[5] Parker GA, Pearson RG. A possible origin and adaptive significance of the mounting behaviour shown by some female mammals in oestrus. J Nat Hist 1976; 10: 241-5.

[6] Dagg AI. Homosexual behavior and female-male mounting in mammals - a first survey. Mammal Rev 1984; 14: 155-85.

[7] Harvey PH. A bestiary of chaos and biodiversity. Nature 1999; 397: 402-3.

[8] Roughgarden J. Evolution's rainbow: Diversity, gender, and sexuality in nature and people. Berkeley: University of California Press; 2004.

[9] Sommer V, Vasey PL, Eds. Homosexual behaviour in animals: An evolutionary perspective. Cambridge: Cambridge University Press; 2006.
[10] MacFarlane GR, Blomberg SP, Kaplan G, Rogers LJ. Same-sex sexual behaviour in birds: Expression is related to social mating system and state of development at hatching. Behav Ecol 2007; 18: 21-33.

[11] Poiani A, Dixson A (in prep.). Animal homosexuality: A biosocial perspective.

[12] Tinbergen N. On the aims and methods of Ethology. Z Tierpsychol 1963; 20: 410-33.

[13] Kotrschal K, Hemetsberger J, Weiss BM. In: Sommer V, Vasey PL, Eds. Homosexual behaviour in animals: An evolutionary perspective. Cambridge , Cambridge University Press 2006; 45-76.

[14] King CE. In: Sommer V, Vasey PL, Eds. Homosexual behaviour in animals: An evolutionary perspective. Cambridge, Cambridge University Press 2006; 77-106.

[15] West-Eberhard MJ. The evolution of social behaviour by kin selection. Q Rev Biol 1975; 50: 1-33.

[16] Emlen ST. The evolution of helping. I. An ecological constraints model. Am Nat 1982; 119: 29-39.

[17] Emlen ST. The evolution of helping. II. The role of behavioural conflict. Am Nat 1982; 119: 40-53.

[18] Vehrencamp SL. Optimal degree of skew in cooperative societies. Am Zool 1983; 23: 327-35.

[19] Vehrencamp SL. A model for the evolution of despotic versus egalitarian societies. Anim Behav 1983; 31: 667-82.

[20] Emlen ST. An evolutionary theory of the family. Proc Natl Acad Sci USA 1995; 92: 8092-9.

[21] Reeve HK, Ratnieks FLW. In: Keller L, Ed. Queen number and sociality in insects., Oxford, Oxford University Press 1993; 45-85.

[22] Reeve HK, Keller L. Tests of reproductive-skew models in social insects. Ann Rev Entomol 2001; 46: 347-85.

[23] Hamilton WD. The evolution of altruistic behaviour. Am Nat 1963 97: 354-356.

[24] Reeve HK, Emlen ST. Reproductive skew and group size: an $\mathrm{N}$ person staying incentive model. Behav Ecol 2000; 11: 640-7.

[25] Alexander RD. The evolution of social behaviour. Ann Rev Ecol System 1974; 5: 325-83.

[26] Crespi BJ, Ragsdale JE. A skew model for the evolution of sociality via manipulation: Why it is better to be feared than loved. Proc R Soc Lond B 2000; 267: 821-8.

[27] Kokko H. Are reproductive skew models evolutionarily stable? Proc R Soc Lond B 2003; 270: 265-70.

[28] Emlen ST. Reproductive sharing in different types of kin associations. Am Nat 1996; 148: 756-63.

[29] Magrath RD, Heinsohn RG, Johnstone RA. In: Koenig WD, Dickinson JL, Eds. Ecology and evolution of cooperative breeding in birds. Cambridge, Cambridge University Press 2004; 157-76.

[30] Koenig WD, Pitelka FA. In: Alexander RD, Tinkle DW, Eds. Natural selection and social behavior: Recent research and new theory, New York, Chiron Press 1981; 261-80.

[31] Brown JL. Helping and communal breeding in birds: Ecology and evolution, Princeton, Princeton University Press 1987

[32] O'Grady JJ, Brook BW, Reed DH, Ballow JD, Tonkyn DW, Frankham R. Realistic levels of inbreeding depression strongly affect extinction risk in wild populations. Biol Cons 2006; 133: 42 51.

[33] Bennett PM, Owens IPF. Evolutionary ecology of birds: Life histories, mating systems and extinction, Oxford, Oxford University Press 2002

[34] Cézilly F, Préault M, Dubois F, Faivre B, Patris B. Pair-bonding in birds and the active role of females : a critical review of the empirical evidence. Behav Proc 2000; 51: 83-92.

[35] Hasselquist D, Sherman PW. Social mating systems and extrapair fertilizations in passerine birds. Behav Ecol 2001; 12: 455-66.

[36] Trivers RL. Parent-offspring conflict. Am Zool 1974; 14: 249-64.

[37] Ridley J, Sutherland WJ. Kin competition within groups: the offspring depreciation hypothesis. Proc R Soc Lond B 2002; 269: 2559-64.

[38] Felsenstein J. Phylogenies and the comparative method. Am Nat 1985; 43: 300-11.

[39] Sibley CG, Ahlquist JE. Phylogeny and classification of birds. A study in molecular evolution. New Haven: Yale University Press; 1990

[40] Mindell DP, Sorenson MD, Huddleston CJ, Miranda HCJr, Knight A, Sawchuk SJ, Yuri T. In: Mindell DP, Ed. Avian molecular evolution and systematics, San Diego, Academic Press 1997; 213-47. 
[41] Slack KE, Jones CM, Ando T, et al. Early penguin fossils, plus mitochondrial genomes, calibrate avian evolution. Mol Biol Evol 2006; 23: 1144-55.

[42] Livezey BC, Zusi RL. Higher-order phylogeny of modern birds (Theropoda, Aves: Neornithes) based on comparative anatomy. II Analysis and discussion. Zool J Linn Soc 2007; 149: 1-95.

[43] Livezey BC. A phylogenetic classification of waterfowl (Aves: Anseriformes), including selected fossil species. Ann Carn Mus 1997; 66: 457-96.

[44] Sheldon FH, Slikas B. Advances in ciconiiform systematics 19761996. Col Waterb 1997; 20: 106-14.

[45] Friesen VL, Baker AJ, Piatt JF. Phylogenetic relationships within the Alcidae (Charadriiformes: Aves) inferred from total molecular evidence. Mol Biol Evol 1996; 13: 359-67.

[46] Crochet P-A, Bonhomme F, Lebreton J-D. Molecular phylogeny and plumage evolution in gulls (Larini). J Evol Biol 2000;13: 4757.

[47] Thomas GH, Willis MA, Székely T. A supertree approach to shorebird phylogeny. BMC Evol Biol 2004; 4: 28.

[48] Baker AJ, Pereira SL, Paton TA. Phylogenetic relationships and divergence times of Charadriiformes genera: multigene evidence for the Cretaceous origin of at least 14 clades of shorebirds. Biol Lett 2007; 3: 205-9.

[49] Fain MG, Houde P. Multilocus perspectives on the monophyly and phylogeny of the order Charadriiformes (Aves). BMC Evol Biol 2007; 7: 35 .

[50] Christidis L. Phylogeny and systematics of estrildine finches and their relationships to other seed-eating passerines. EMU 1987; 87: 119-23.
[51] Irestedt M, Johansson US, Parsons TJ, Ericson PGP. Phylogeny of major lineages of suboscines (Passeriformes) analysed by nuclear DNA sequence data. J Avian Biol 2001; 32: 15-25.

[52] Ericson PGP, Johansson US. Phylogeny of Passerida (Aves: Passeriformes) based on nuclear and mitochondrial sequence data. Mol Phyl Evol 2003; 29: 126-38.

[53] Barker FK, Cibois A, Schikler P, Feinstein J, Cracraft J. Phylogeny and diversification of the largest avian radiation. Proc Natl Acad Sci USA 2004; 101: 11040-45.

[54] Spicer GS, Dunipace L. Molecular phylogeny of songbirds (Passeriformes) inferred from mitochondrial 16S ribosomal RNA gene sequences. Mol Phyl Evol 2004; 30: 325-35.

[55] Sheldon FH, Whittingham LA, Moyle RG, Slikas B, Winkler DW. Phylogeny of swallows (Aves: Hirundinidae) estimated from nuclear and mitochondrial DNA sequences. Mol Phylog Evol 2005; 35: 254-70.

[56] Treplin S. Inference of phylogenetic relationships in passerine birds (Aves: Passeriformes) using new molecular markers. 2006; PhD Dissertation, University of Postdam.

[57] Midford PE, Garland TJr, Maddison WP. 2005. PDAP package of Mesquite.Version 1.07.

[58] Maddison WP, Maddison DR. 2006. Mesquite: a modular system for evolutionary analysis. Version $1.1 \mathrm{http} / / /$ mesquiteproject.org.

[59] Grafen A. The phylogenetic regression. Phil Trans R Soc Lond B 1989; 326: 119-57.

(C) Aldo Poiani; Licensee Bentham Open.

This is an open access article licensed under the terms of the Creative Commons Attribution Non-Commercial License (http://creativecommons.org/licenses/ by-nc/3.0/) which permits unrestricted, non-commercial use, distribution and reproduction in any medium, provided the work is properly cited. 